\title{
Aligning post-merger information systems with corporate strategies. Empirical evidence in a bank merger
}

\author{
Renata Paola Dameri \\ Department of Economics, University of Genova, Italy \\ Via Vivaldi, 2 \\ 16126 Genova, Italy \\ dameri@economia.unige.it
}

\begin{abstract}
Information System integration is one of the most important challenges in post merger activities. The role of Information System in supporting business processes, products, customer relationships and the daily work of employees in the target company is central. For this reason, the IS rdesign in post-merger activities is both a threat and an opportunity: a threat because to fail the IS integration could mean the failure of the merger; an opportunity, because to redesign the IS could help to better align it with the new strategic goals of the post-merger company and to gain better performance. However, merged companies generally aims especially at operational goals regarding IS integration, such as cost savings and risk reduction. They overlook the opportunity to align the target IS with M\&A strategic aims. In this paper, the author studies the opportunity deriving from a M\&A operation, to align IS with corporate strategies; theoretical considerations are supported by empirical evidence in a business case, regarding the most important Italian M\&A in the banking sector. The paper suggests a set of business practices and assessment instruments to support management choices in post-merger IS integration and alignment.
\end{abstract}

\section{Indexing terms/Keywords}

IS integration, M\&A, strategic alignment, IS redesign, banking sector.

\section{Academic Discipline And Sub-Disciplines}

Business administration; Information Systems; Bank and Finance;

\section{SUBJECT CLASSIFICATION}

E.g., Mathematics Subject Classification; Library of Congress Classification

\section{TYPE (METHOD/APPROACH)}

The paper includes both a large literature review about the topic, and a case study about an excellent company.

\section{Council for Innovative Research}

Peer Review Research Publishing System

Journal: International Journal of Management \& Information Technology

Vol. 5, No. 1

editor@cirworld.com

www.cirworld.com, member.cirworld.com 


\section{INTRODUCTION}

In mergers or acquisitions (M\&A) the integration of information systems is a crucial problem. Indeed, to really realise an integrated company, it is necessary to integrate human resources, customers, products and business processes. The Information System (IS) role in supporting business processes, products, customer relationships and the daily work of employees is central. Information technology is pervasive in all the business activities (Porter and Millar 1985), and the information system should support all the operations in the best way, to realise the higher performance (Weill and Ross 2004). For these reasons, the IS redesign in post-merger activities is both a threat and an opportunity: a threat, because to fail the IS integration could mean the failure of the merger; an opportunity, because to redesign the IS could help to better align it with the new strategic goals of the post merger company and to gain better performance.

However, merged companies often focus their attention especially on the threats, mainly pursuing operational goals in integrating IS. Literature shows that the most important goals in integrating post merger IS are to reduce cost, to gain savings, to standardise processes and applications. Obviously these are important objectives both for the merger itself and for the IS integration, but they should be pursued taking in main consideration the opportunities deriving from the merger. Therefore, the IS change should be managed joining operational goals such as cost reduction and process standardisation, with strategic goals, like strategic alignment of the target IS and the impact of IS on the business performance (McKiernan and Merali 1995).

The goal of this paper is to analyse and to define the procedures to be applied in integrating IS in a post merger environment, aiming at the maximum fit between IS and the merger strategici goals, reaching in the meantime operational goals such as efficiency and standardisation. The author presents relevant literature and conducts an excellent business case. The studied company is Intesa San Paolo, the larger Italian bank and one of the most important ones at European level; the bank gained its position through a joint venture between Intesa Bank and San Paolo Company in 2007. The business case is interesting both for the technical success of IS integration in a short time, and for the primacy given to the strategic support by IS to the merger.

The business case study includes in-depth understanding of the strategic goals of the merger; it analyses the factors affecting the design of the target applications portfolio and the assessment instruments applied to support the IS integrations process. The empirical evidence emerging from the case study has been collected during three years before, during and after the integration activity. Internal and external documents regarding the merger have been analysed, and semi-structured interviews have been conducted, involving four top maganers in the IS Department of the company. Finally, the complete case study reports have been reviewed and confirmed by the $\mathrm{ClO}$ and his staff of Intesa San Paolo.

Expected results are the in-depth understanding of assessment axes to be considered in designing the target IS after a merger and best practices to be applied in similar business cases.

\section{INTEGRATING INFORMATION SYSTEMS AFTER MERGER AND ACQUISITION}

The topic regarding IS integration and redesign after a merger has ever been interesting, since IT entered enterprises (Burton 1972). However, IS integration has ever been seen like a problem, instead of an opportunity to change the IS in order to better support processes and strategies of the merged company. The reason is that IS is really pervasive in business operations and essential for carrying out daily activities. The process to integrate IS during a merger could be critical for the success or the failure of the operation. After a merger, therefore, the main goal of the target company's ClO is to grant business continuity, IS affordability and data security (Stylianou, Jeffries and Robbins 1996). Less importance is often given to strategic alignment and quality of the merged IS.

Moreover, corporate mergers generally aim at gaining savings from synergies in operations, human resources and business services. For these reasons, $\mathrm{ClOs}$ are asked to integrate information systems deriving from the merged companies on the shortest time, with the lower cost, reducing the technical and operational risks. The attention is focused on the operational and technical functioning of the post-merger IS, with the lowest impact on people, business processes and customers.

To reach the IS integration in the easier way and shortest time, important objectives are neglected and simply implied in the integration process; it means that $\mathrm{ClO}$ doesn't have explicit goals regarding time, cost or risk, and the quality of the resulting IS and of the integration process could be not clearly planned nor effectively evaluated (Robbins and Stylianou 1999b). Instead IS redefinition needs to explicitly consider some crucial aspects affecting the success of the merger and the well functioning of the target IS, such as complexity reduction, centralisation of control, and well-conceived IT governance based on the organisational architecture of the newco.

Analysing the literature over forty years, we can observe a shift from operational aspects to strategic goals; it means that researchers are aware that technical success of an integration by itself is not able to grant the corporate effectiveness of the IS. We analysed 113 documents in scholarly journals (indexed and peer reviewed) from 1972 to today. During the first twenty years the most frequent topics are technical difficulties in IS integration and its impact on corporate accounting. After nineties, the attention is more and more focused on aspects affecting the quality of the target IS after mergers and the impact on company success, strategic positioning and business performance. The survey points out the greater importance of new topics, more linked with the economic success of the merger, instead of the technical result of the IS integration. 
Youngjin, Lyytinen and Dongcheol (2007) studied the importance of knowledge sharing in post-merger IS, considering knowledge like a critical success factor for the pursuing of strategic goals (Dameri and Bonfante 2007). Instead, poor studies before this date considered knowledge sharing important in IS integration and a driver for the outcome of the merger (Dameri 2002). Mehta and Hirscheim (2007) put strategic alignment at the centre of their comprehensive model, to drive decisions regarding IS integration after M\&A. The strategic dimension is considered like a crucial factor affecting IS shaping. However, the authors point out that several companies are not able to include corporate strategic goals in their decision framework regarding IS integration: they misalign, especially in the early post-merger period. It means a negative impact on reaching synergy goals that drove much of the initial integration decision making. It appears more and more clear that the consolidation on the bottom line is achieved not only pursuing merely savings by integrating and streamlining IS and IS operations; the success is reached by carefully structuring a well aligned IS, built around business needs and specific characteristics of the merged company (Anonymous 2004).

Nevertheless, the business reality is quite different. We cannot find large surveys on $M \& A$, regarding the IS integration. $M \& A$ are exceptional management operations; they involve two or few companies in a particular, specific joint and it is difficult to find common characteristics in several M\&A: industrial sector, company dimensions, M\&A strategic goals are aspects able to deeply affect the nature of each M\&A. However, examining the 113 documents, several business cases have been found, each of them regarding one or a few M\&A. The analysis of all these business cases shows that companies pay low attention at IS alignment with corporate strategies.

For the first, IS is never considered in pre-merger analysis of potential target companies, even if IS is an important organisational factor. IT has not a role in negotiating the acquisition price nor in evaluating candidates for takeovers (BukLew, Wardle and Pliskin 1992). IS integration is not a strategic priority; IS merger is often reached only three or four years after the M\&A. Companies prefer to maintain separate IS and to merge just the financial data for accounting, mandatory disclosure or compliance, for example in banking sector (Mehta and Hirscheim 2007, ABA 1985). But an incomplete IS integration has a strong negative impact both on economic and on strategic goals of the M\&A (Leger and Young 2005). On the economic side, to maintain not perfectly integrated IS means duplicated IS activities and higher cost; it means also not integrated business processes and less efficient operations. On the strategic side, not to integrate IS means not to integrate the business. If the M\&A has only financial goals, it could not be a problem. But if the M\&A has the objective to really join two different companies, unifying their products portfolio, their customers portfolio, their human resources and integrating two different business cultures, not to integrate IS means not to reach the expected M\&A results.

The survey on the document set shows also that there is ever a strong focus on procedures regarding how to manage the integration process (Giacomazzi et. al 1997, Brunetto 2006, Alaranta 2005, Alaranta and Hendersson 2008). Several researchers suggest IS integration models, including the analysis of organisational contingencies, the implementation of change management frameworks in M\&A IS integration, and possible choices for hardware and software configuration. We can note also a hierarchical importance given in business cases to different topics regarding IS integration in M\&A. It appears like a bottom-up pyramid, with technical aspects on the top (IS technical architecture), followed by data integration, strategic integration and finally (but not ever) IS governance redesign (Figure 1).

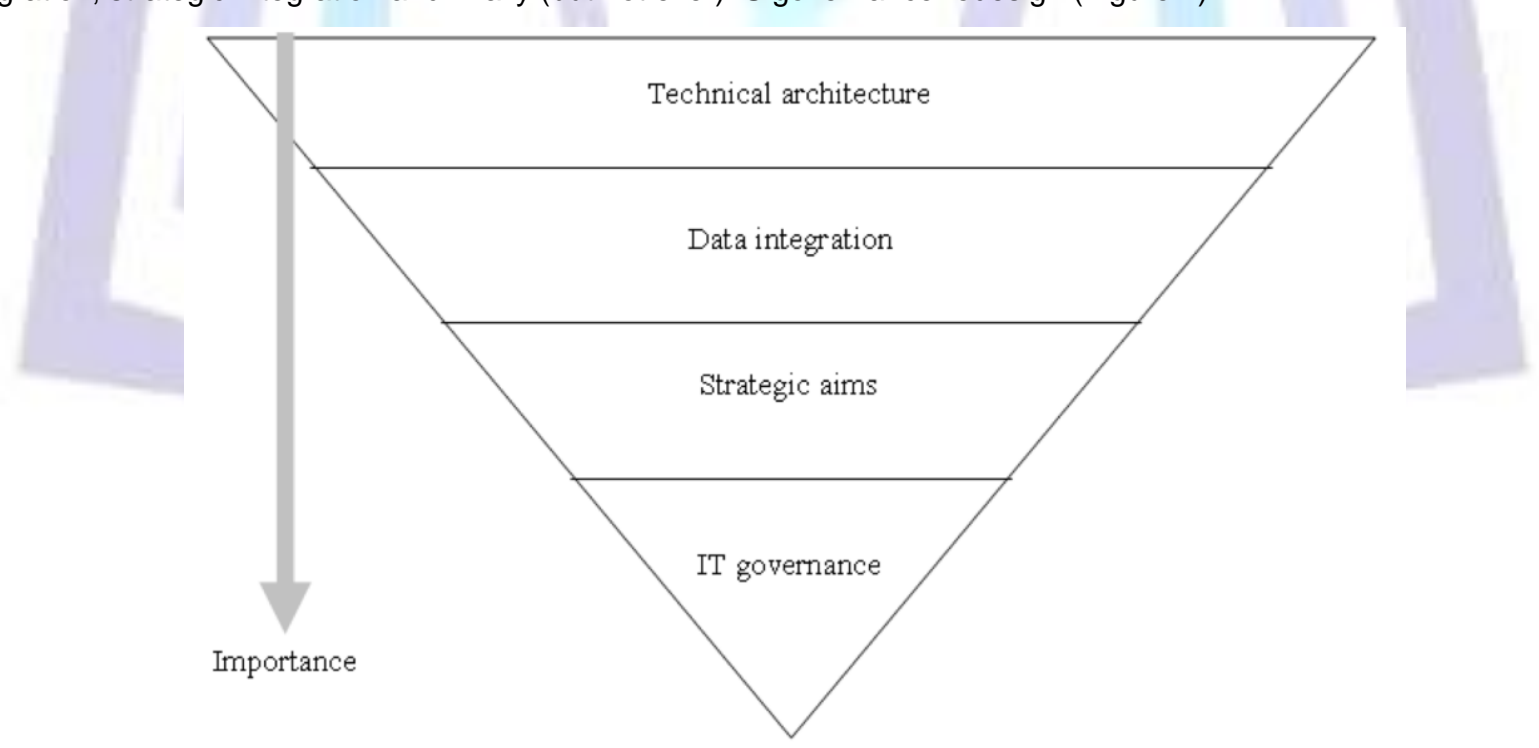

Fig 1: Hierarchical importance of different topics affecting post-merger IS integration: The inverted pyramid

In studying Intesa San Paolo (ISP) business case, two are the most evident differences respect to the literature: the importance of IS alignment with corporate strategic goals deriving from the merger, and the comprehensive framework to assess the integration choices. In managing the IS integration, the $\mathrm{CIO}$ and his staff took into consideration all the goals together, but with the primacy of the best alignment between the IS vision and the corporate strategic vision. The hierarchical importance of different drivers for IS integration planning and implementation has been completely removed. Strategic goals drove integration choices - the "what" of the process, operational goals drove the change management 
process - the "how". This decisional and normative model permitted to accomplish concurrently with both strategic and operational requirements affecting post-merger IS integration.

\section{INTESA SAN PAOLO: THE BUSINESS CASE}

At the end of 2006, two of the major European banks and the largest Italian ones, Banca Intesa and San Paolo decided to merge. It was one of the most important merger in Italy and in Europe, too. The new company, Intesa San Paolo (ISP) is the ninth European bank; it is Italian market leader in the main financial business, it has more than 5.800 branches and 12 million customers environ.

The aims of this merger were to become Italian leader and to compete on the international markets, opening to global business more than in the past. However, ISP wanted not only to maintain its local strategic positioning, but to strengthen its own very specific vision and mission, based on the "Land Banks" idea: that is, a bank with a strong rooting in the local environment so to be really near to the customers, to better satisfy their needs and to gain their trust. ISP based its post merger strategic choices on a glocal view: to remain local, but in the meantime to be large enough to compete on the global financial markets (Intesa San Paolo 2006a). The merger strategic goals could be summarised in four points (Intesa San Paolo 2006b):

- $\quad$ Process integration: to unify business processes and organizational structures to gain savings and efficiency, but also to create a unique way-to-do all over the company;

- Products portfolio integration: to improve the quality of the offer to the customers, maintaining the products specificity for each business segment and geographical area and gaining customers' trust;

- $\quad$ Land bank, to defend the distinctive look and strategic positioning of ISP on the internal market;

- $\quad$ Larger dimension, to support the business growth on the international financial markets (Figure 2).

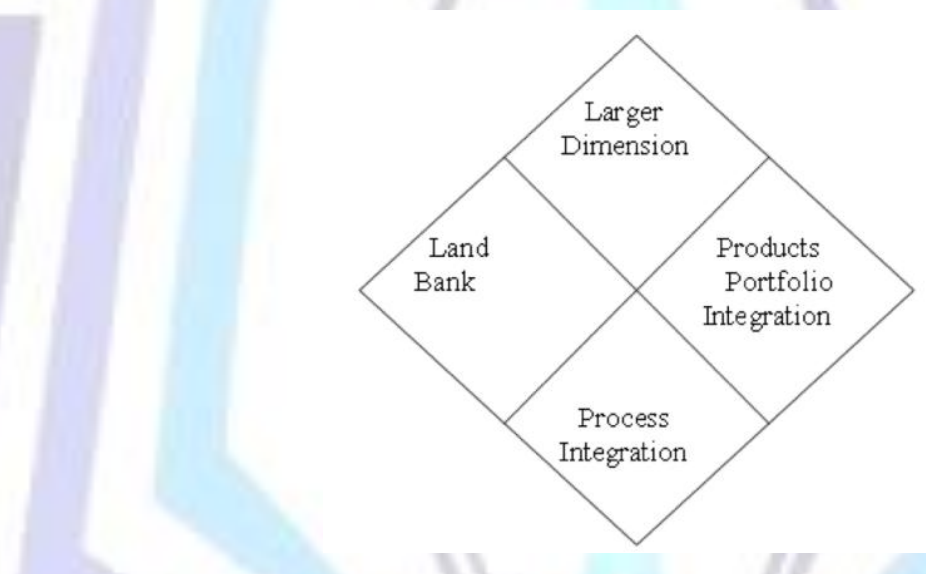

Fig 2: The strategic goals of ISP merger

Four aspects were more important to drive the IS redesign (Intesa San Paolo 2006c):

- The need to really integrate all the management aspects, from human resources to business processes, from customer relationships to products;

- The equal importance of the two merged banks, that prevent the supremacy of one company (with its own business model and IS) over the other one;

- $\quad$ The large dimensions of the merger, a real challenge for the management, and also for the $\mathrm{CIO}$;

- The prior merger experience of the two banks Banca Intesa and San Paolo, that permits to apply the already tested IS integration process, so that ISP could focus only on the strategic aspects of the merger.

The important role of the information systems in supporting the banking business and the pervasivity of IT in financial processes and products are drivers of the need to real integrate IS in this merger; it depends also on the specific strategic choices of ISP: to realize a really integrated bank, with the same customers, products and operations, and people really aware to belong to a unique organisation, the IS should fully support the merge of the business.

Therefore:

- $\quad$ to really integrate all the business functions, ISP should choice which application systems to implement in the post merger branches (Miklitz and Buxmann 2007).

- The equal importance of the two merged banks drove towards a best-of-breed integration strategy (Bruning and Pedain 2007). 
- The large dimensions forced ISP to realize the IS integration as fast as possible, to gain very high cost savings reducing risks, complexity and compliance default (Johnston and Yetton 1996).

- $\quad$ The prior merger experience helped ISP in putting strategic needs and operational needs on the same basis, without too much worries regarding integration process models: the company simply applied the internal, consolidated best practices (Henningsson and Carlsson 2011).

After studying the ISP business case, thanks to the large quantity of internal documents made available to us by ISP and the interviews with the $\mathrm{CIO}$ and his staff, we can define the comprehensive integration model applied by ISP (Figure 3). This model takes into consideration both the operational and the strategic criteria, to drive integration choices and activities. Operational aspects are seen like constraints to respect, strategic aspects are seen like goals to be reached.

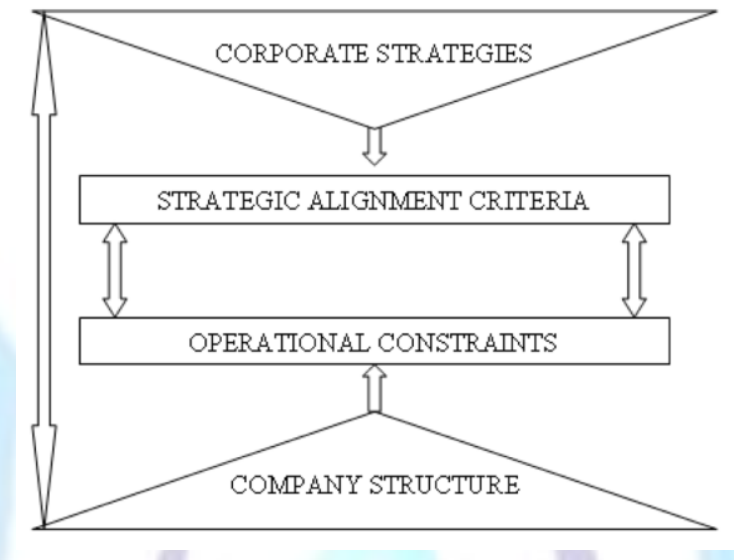

Fig 3: The ISP comprehensive integration model

To implement the merged information system, ISP developed a structured and formalised assessment framework, to support choices regarding operational constraints, strategic alignment and the comprehensive strategic vision of the target information system. This framework is described below.

\section{THE ASSESSMENT INTEGRATION FRAMEWORK}

At the beginning of 2007, IS department of the merged bank started its integration program. This program is based on an assessment framework, to support operational constraints and strategic alignment criteria. Before the framework implementation however, ISP defined the strategic vision of the target IS and the fundamental values to be pursued in redesigning it (San Paolo 2006, Banca Intesa 2006). To support the IS strategic vision definition, the scenario technique has been used, with the support of several panels of experts, from all the main business and support activities of the bank. Three aspects are described below:

- $\quad$ The IS strategic vision design;

- The strategic alignment criteria and their evaluation;

- The constraints assessment.

\subsection{The IS strategic vision design}

In accordance with the strategic goals of the merger and with the specific business sector of Intesa San Paolo (banking), the strategic vision of the IS is built on three pillars:

- Business complete integration;

- Support to the"Land Bank" strategic positioning;

- Technological and operational security, risk prevention, compliance and affordable disclosure.

The third pillar is a duty and it will impact especially on cost and risk constraints.

The first pillar enables integrated governance of business results, at group level and at each bank level, but also the effective standardization of business processes and products all over the corporation. It means that all the banks and branches should use the same applications. The importance of this vision derives from the aim of ISP, to offer to all the customers the same products, prices and way-to-do, so that they are aware to belong to the same bank. Therefore, the first pillar obliges to consider for the first the choice of a target portfolio applications, to be implemented in all the business branches and departments, as soon as possible, to realize the bank integration especially on the market.

The second pillar refers to the "Land Bank" strategic positioning; Intesa San Paolo bases all its competitive distinction on the "glocal" view: to enlarge its business on the international markets, maintaining a strong link with the specificity of Italian regional environments. It requires to preserve the specific characteristics and autonomy of all the banks of the group, but 
granting software standardization. The second pillar is also a directive for the strategic alignment, to standardize maintaining the business specificity.

The technical solution to support these strategic requirements - glocalization and specificity on one side, integration and software standardization on the other side - is to organize the information system in clones: each legal entity has a dedicated copy of the same core banking applications (Figure 4).

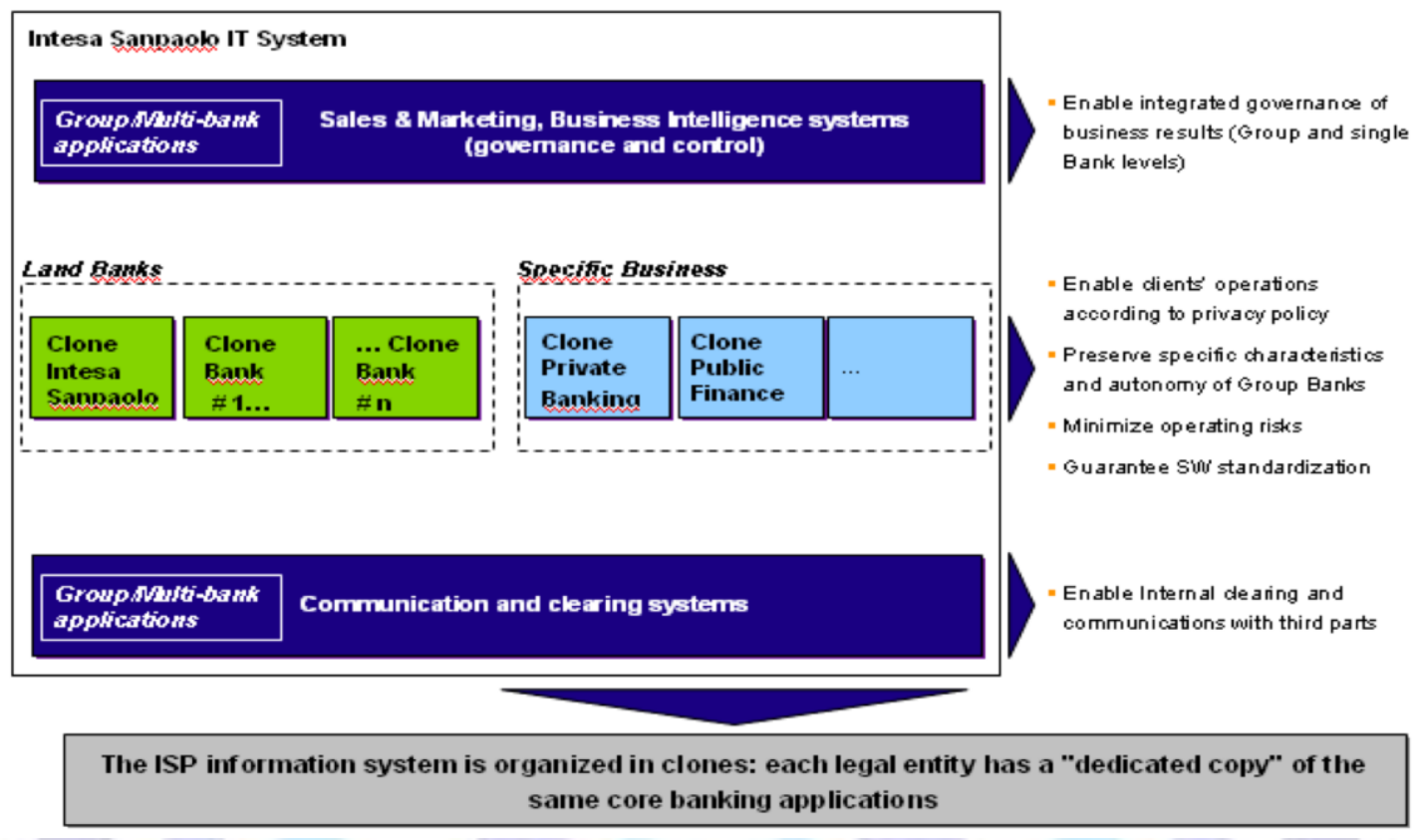

Fig 4: The strategic vision is built on three pillars and the technical solution is the dedicated copies (clones)

(Source: ISP information system integration project)

The merged IS is built on three levels. At the first level, the Group Multi Bank Applications are software solutions aiming at managing all the corporate operations, especially financial, accounting and disclosure ones. Moreover, data are collecting to support the integrated governance of business results, regarding both the whole group and each single bank.

At the central level, business applications are organized in two subsets; the first subset includes software solutions to support the Land Bank strategy, that is, all the services support for daility operations in all the branches spread all over Italy. The other subset includes software modules devoted to specific business activities. These applications are linked into a unique information systems duplicated for each bank, that is, different legal entity belonging to the group. This IS clone hab been implemented aiming at both strategic anf operational goals, such as: to enable clients' operations according to privacy policy, to preserve specific characteristics and authonomy of each Group Bank, to minimize operating risks, to guarantee software standardization, and so on.

Ath the third level, another shared application is available, to manage the coomunication at clearing systems for the Group. It enables internal clearing and coomunications with third parts.

\subsection{The strategic alignment criteria and their evaluation}

Depending on the strategic directives, integration and glocalisation, Intesa San Paolo analysed the source Information Systems and designed two scenarios:

- $\quad$ Banca Intesa scenario: the Banca Intesa IS would become the target IS;

- San Paolo scenario: the San Paolo IS would become the target IS.

Before the merger, Banca Intesa had a centralised information system, based on a products/customers matrix. The main modules of the IS were: Retail banking, Corporate and finance, Private equity, Public administrations, Mid-time business. San Paolo, on the contrary, had a federated information system: each bank of the group had its own information system, standardised respect to a unique architecture. Each information system included all the business processes: retail, corporate and finance, mid-term and so on. Both the banks had other modules, regarding minor or non-core activities.

Therefore, the source information systems were very different each others. To support the target system selection, ISP defined four evaluation axes to be applied to the scenarios:

- Business coverage;

- Speed of completion the migration path;

- Costs;

- Risks. 
The evaluation is qualitative and it is made on five scores, from 0 to 4 ; the results are graphically highlighted, to better understand the final assessment of the different scenarios and better support the selection. Scores are given by several experts in different business areas or support activities, both from the business and from the Information Systems Department. The evaluation of the first axis is made to support the strategic alignment, the evaluation of the latter three ones measures the operational constraints.

The final choice has been made taking into consideration all the axes, with the primacy of the strategic aims (Carlosson et. al. 2011, Robbins and Stylianou 1999a). However, no one of the two source ISs was adequate for the new strategic architecture of ISP. Therefore, ISP choose the best of breed integration scenario, because it was able to support the effective merge of Land Bank, already implemented by San Paolo, with Specific Business, covered by Intesa modules. San Paolo scenario was dominant, as San Paolo IS better fit the Land Bank strategy, but several specific applications were implemented in the final IS using Intesa software. Modules have been selected depending on their better corresponding to the strategic model, using the qualitative scores given by the business experts. It also granted the best integration of business processes, products and customers portfolio (Sabroux et. al. 2010). Costs and risks are used like constraints, that is: after the selection of the best-of-breed scenario for well-aligned IS, best costs and risks are the constraints to be observed.

\subsection{The constraints assessment}

After the choice of the target IS, time, costs and risks have been assessed, to give to the IS Department clear goals and constraints to be respected. The two scenarios have been compared respect to the three remaining axes described above.

Speed axis was evaluated taking into consideration the time required to roll out all the applications; it depends on the number of changes to do. Best-of-breed integration strategy was able to reduce the migration time, because it implemented the Land Bank applications already used by San Paolo banks and branches, that were more than Intesa ones; it permitted also to choice the more innovative solutions in the merged application portfolio. Moreover, this Land Bank IS architecture was more suitable with the strategic vision and therefore required less adjustments. The more the branches already use Land Bank IS, the higher the integration readiness.

To assess the risk axis, two aspects have been evaluated: IS integration impact on customers and on organisational and technological change. The technical change has been evaluated considering three important aspects for the future of the bank: scalability, business continuity, data recovery. Organisational change has been evaluated measuring the number of employees, users, branches and transactions impacted by the IS redesign. San Paolo scenario had a higher score, because it granted better cost savings and lower risks. Slight higher costs and risks were produced by the best of-breed strategy, but it was accepted, in order to obtain a better target IS. However, the difference was low and the savings after the complete IS integration have been really satisfactory.

The impact on customers played a crucial role in defining the IS target and the best-of-breed perimeter. ISP evaluated the number of customers, channels and branches involved in the IS change. IS affordability, business continuity, but also wellconceived business processes and products are crucial to maintain the customers' loyalty and trust. Therefore, beside to grant time, cost and synergies constraints, to reduce the impact on customers has been the main goal of the integration procedure, influencing the IS selection too. Also in this case San Paolo scenario was the better solution, integrated by some best-of-breed choices. In Figure 5 we can see an example of the qualitative evaluation of one of the assessment axes (Impact on customers). Similar evaluations have been made for the other axes: business coverage, speed and costs.

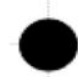

The number of users of electronic channels (Internet, call centers, corporate banking) is about the same

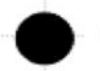

- In Sanpaolo scenario, during the "core banking" system migration, are involved ImCicls customers

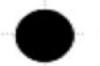

In Sanpaolo scenario are involved Financial Institutions clients during the migration

- The different length of the account number (12 digits in Sanpaolo, 10 digit in Intesa) will require, probably, the renumbering of all reports (Intesa scenario)

Fig 5: The risk evaluation: Impact on customers (Source: ISP information system integration project) 


\section{$5 \quad$ BEST PRACTICES AND LESSONS LEARNED}

The literature review presented in this document outlines that operational goals are often at the first place in post-merger IS integration. After analysing several business cases, this study concludes that cost savings and risk mitigation are often the main drivers in managing the post-merger information system redesign.

The Intesa San Paolo business case is therefore interesting, as the company put the IS strategic alignment with postmerger strategic goals at the first place for its own IS integration process aim. Several best practices came out from the ISP integration activity are useful and could be applied to other M\&A cases, helping in both realising IS strategic alignment and in reaching operational and economic objectives.

The most important best practice is the primary definition of the target IS strategic vision, in accordance with the strategic mission and goals of the merged company. Indeed, companies generally prefer the absorption integration strategy (Miklitz and Buxmann 2007), because it permits to reduce time, costs and risks. However, the selected existing system is strategically aligned with strategies before the M\&A and it could be an obstacles in gaining the M\&A synergies. To put the strategic alignment at the core of the integration strategy is helpful also to drive technical and operational choices, as the target IS vision defines the general policies to support the IS redesign.

Another important best practice regards the adoption of a formalised evaluation framework, to assess the best solution to be chosen. Best-of-breed integration strategy could have several disadvantages such as difficulties in component evaluation and in realising synergy potentials. To use the graphical, qualitative evaluation framework helps both technical managers and $\mathrm{CIO}$ to drive the selection of application systems, and business managers to be aware of both advantages and difficulties connected with the target IS. Moreover, the different scenarios or integration strategies could be compared each others in a clear manner, helping to choice the best solution and to justify the choice. The involvement of business experts is another success factor, because it improves the acceptance rate of the new system by the users and the coverage of functional requirements.

The business case studied in this article is source of important lessons learned. For the first, to consider cost and risk measures like constraints instead of like goals, permits to focus the efforts on the strategic aspects of the IS integration. The ISP business case demonstrates that the IS strategic vision drives also to better savings and risk mitigation; slight higher cost and risk are accepted, because they produce better results in terms of IS quality. So that the ISP integration strategy balances quality and quantity goals, and the target IS grants effectiveness, security and cost reduction.

The ex-post evaluation of the integration process shows that all the goals have been reached, except for slight higher cost. But the most important strategic aims: low impact on the customers, full integration of business and products in the shortest time, Land Bank implementation have been pinpointed. One of the main success factors was also the prior experience of both the merged banks in M\&A operations.

\section{REFERENCES}

[1] Alaranta, M. (2005). Integrating the enterprise systems after a merger: managing the change in a manufacturing company. ECIS 2005 Proceedings.

[2] Alaranta, M., Henningsson S. (2008). An approach to analyzing and planning post-merger IS integration: Insights from two field studies. Information Systems Frontiers 10, no. 3, (July 1): 307-319.

[3] Alaranta, M., Vijanen, M. (2004). Integrating the personnel after a merger - Managing the challenges and opportunities. ECIS 2004 Proceedings.

[4] Anonymous (2004). Tying the knot: IT systems in a merger. The McKinsey Quarterly no. 4, (January 1 ): 1.

[5] Banca Intesa (2006), Bilancio sociale.

[6] Brunetto, G. (2006). Integrating information systems during mergers: integration modes typology, prescribed vs constructed implementation process. ECIS 2006 Proceedings.

[7] Buck-Lew, M., Wardle, C. E., and Pliskin, N. (1992). Accounting for Information Technology in Corporate Acquisitions. Information \& Management 22, no. 6, (June 1): 363.

[8] Carlsson, S., Henningsson S., Hrastinski S., Keller C. (2011). Socio-technical IS design science research: developing design theory for IS integration management. Information Systems and eBusiness Management 9, no. 1, (March 1): 109-131.

[9] Dameri R.P. (2002), M\&A and ICT Assets Evaluation. The Case of Banca Intesa. Ninht European Conference on Information Technology Evaluation, Université Paris Dauphine, France - 15-16 July.

[10] Dameri R.P., Bonfante S. (2007), Using IT to Enhance Customers Loyalty and Trust in Retail Banking, ECIME 2007 The European Conference on Information Management and Evaluation, University Montpellier 1, Montpellier, France, 20-21 September.

[11] Fitzgerald G. (2003). Research challenges in information systems. International Journal of Information Management 23, no. 4, (August 1): 337-344.

[12] Giacomazzi, F. , Panella, C. , Pernici, B. , Sansoni, M. (1997). Information systems integration in mergers and acquisitions: A normative model. Information \& Management 32, no. 6, (November 1): 289-302. 
[13] Henningsson, S., Rukanova B. , Hrastinski S. (2010). Resource Dependencies in Socio-Technical Information Systems Design Research. Communications of the Association for Information Systems 27, , (July 1): 777.

[14] Henningsson, S., Carlsson, S. (2011). The DySIIM model for managing IS integration in mergers and acquisitions. Information Systems Journal 21, no. 5, (September 1): 441-476.

[15] Intesa San Paolo (2006a), Documento informativo. Fusione per incorporazione in Banca Intesa SpA.

[16] Intesa San Paolo (2006b). Progetto di fusione.

[17] Intesa San Paolo (2006c). Relazione illustrativa ex art. 2501 quinques codice civile.

[18] Johnston, K. D., Yetton, P. W. (1996), Integrating information technology divisions in a bank merger. Fit, compatibility and models of change. Journal of Strategic Information Systems 5, 189-211.

[19] Katerattanakul, P., Kam, H., Lee J., Hong S. (2009). Migrating Legacy Systems in the Global Merger \& Acquisition Environment. Journal of Information Systems Education 20, no. 3, (October 1): 281-288.

[20] Krell, K., Matook S., Rohde F. (2011). Development of an IS change reason-IS change type combinations matrix. European Journal of Information Systems 20, no. 6, (November 1): 629-642.

[21] Leger, P., Young, S. (2005). Network effects and the creation of shareholders' wealth in the context of software firm mergers and acquisitions. ECIS 2005 Proceedings.

[22] MacDonald, E. H. (2001). GIS in banking: evaluation of Canadian bank mergers. The Canadian Journal of Regional Science 24, no. 3, (October 1): 419-442.

[23] Mehta, M., Hirschheim, R. (2007). Strategic Alignment In Mergers And Acquisitions: Theorizing IS Integration Decision making. Journal of the Association for Information Systems 8, no. 3, (March 1): 143-149,151-174.

[24] McKiernan, P., Merali,Y. (1995). Integrating information systems after a merger. Long Range Planning 28, no. 4, (August 1): 54.

[25] Miklitz, T., Buxmann, P. (2007), IT standardization and integration in mergers and acquisitions: a decision model for the selection of application systems. ECIS 2007 Proceedings.

[26] Porter M., Millar V.E. (1985). How information gives you competitive advantage. Harvard Business Review Vol 73 Iss 6.

[27] Robbins, S. S., Stylianou, A. C. (1999). Post-merger systems integration: The impact on IS capabilities. Information \& Management 36, no. 4, (October 1): 205-212.

[28] Robbins, S. S., Stylianou, A. C. (1999). Are information intensive organizations more likely to succeed with systems integration resulting from corporate mergers? The Journal of Computer Information Systems 39, no. 3, (April 1): 4448.

[29] Robertson, S., Powell, P. (2001). Managing the IS function during mergers. ECIS 2001 Proceedings.

[30] Sabroux C., Dameri R.P., Saad I. (2010), Driving IS value creation by business process optimization. Theoretical aspects and empirical evidences. ITAIS - The Italian Association for Information Systems Conference, Università di Napoli, 9-10 October.

[31] San Paolo (2006), Bilancio sociale.

[32] Short, J.E., Venkatraman, N. (1992). Beyond Business Process Redesign: Redefining Baxter's Business Network. Sloan Management Review 34, no. 1, (October 1): 7.

[33] Stylianou, A. C, Jeffries, C. J, Robbins, S. S. (1996). Corporate mergers and the problems of IS integration. Information \& Management 31, no. 4, (December 15): 203-213.

[34] Tadalo S., Tsuruoka M. (2002). Ramp new enterprise information systems in a merger \& acquisition environment: A case study. Journal of Engineering and Technology Management 19, no. 1, (March 1): 93-104.

[35] Weill, P., Ross, J. (2004). IT Governance. How Top Performers Manage IT Decision Rights for Superior Results. Harvard Business School Press, Boston MA.

[36] Youngjin Y., Lyytinen K., Dongcheol H. (2007). Closing the gap: towards a process model of post-merger knowledge sharing. Information Systems Journal 17, no. 4, (October 1): 321.

\section{Author' biography with Photo}

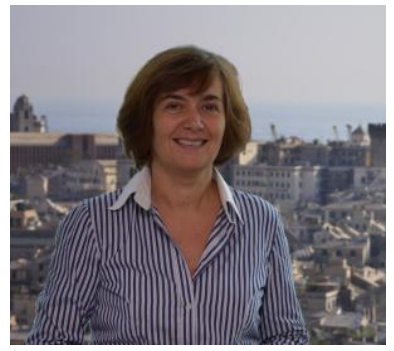

Renata Paola Dameri is researcher in Business Administration at the Department of Economics, University of Genova, Italy. She is Professor of Accounting and of Information Systems in the same University, Professor of IT Governance at Université Paris Dauphine, France, and member of the Information Systems Unit at the SDA Bocconi School of Management in Milano, Italy. Her research fields of interest are: Information Systems, Accounting Information Systems, IT Governance, IS Compliance, Smart city, Sustainable development using ICT, Intellectual capital. 